\title{
The Effect of Using Sawdust as Mixture of Concrete Pipe on Water Absorption and Compressive Strength
}

\author{
Ayende ${ }^{1, *}$ Hernawan Novianto ${ }^{1}$ \\ ${ }^{I}$ Department of Mechanical Engineering of Refinery, Polytechnic of Energy and Mineral Akamigas, 58315, Indonesia \\ *Corresponding author. Email: ayende2018@ gmail.com
}

\begin{abstract}
This article describes an experimental study of the effect of using sawdust as a mixture of concrete pipe on water absorption and compressive strength. This research was inspired by the amount of sawdust waste from sawmills that had not been utilized. For this purpose, 18 specimens were made with four different values for sawdust: iron ore (5\%, $10 \%, 15 \%$, and $20 \%)$. Each specimen has the composition of cement: iron ore (1:4), and water: cement $(0.5 \%)$. This research was conducted at PT Indal Steel Pipe. This research to analyse the effect of using sawdust as a mixture of concrete pipe on water absorption and compressive strength. Experimental method using compression test and water absorption test has been used to this study. Main finding from this study showed the higher the composition of sawdust increased water absorption and reduced the compressive strength of the concrete pipe. This study will be useful to reduce waste pollution and improved concrete pipe material in term of production cost.
\end{abstract}

Keywords: Sawdust, Concrete Pipe, Water Absorption, Compressive Strength.

\section{INTRODUCTION}

In offshore oil and gas transportation operations, it is common to use carbon steel pipes equipped with concrete that act as ballast. Concrete pipe is a mixture of several components with a certain composition, where in general the concrete-forming material as a ballast for carbon steel pipes consists of iron ore, cement and water.

Various studies have been conducted to observe the impact of adding concrete constituent materials, some of which have been carried out by Kamran Amini et. al [1]. In his research, Amini observed the effect of the characteristic mix proportion on concrete performance, including cement slag replacement, air content, water-tocement ratio $(w / \mathrm{cm})$, and paste volume. Amini's research results show that the use of slag cement shows a significant increase in concrete performance, while increasing air content shows a tendency to result in lower concrete strength and higher shrinkage. Research related to concrete characteristics was also carried out by Aref Shafiei Dastgerdi [2], where in his research, Dastgerdi observed the effect of concrete mixture components, proportions, and compressive strength on crack parameters. The results of Dastgerdi's research showed that increasing the angle, size and volume of the aggregate, and decreasing the w/c ratio increased the fracture toughness by $30 \%$. Dastgerdi also reported that changes in paste, fly ash and air cavity content greatly affected the fracture toughness. In another study, the addition of certain components to obtain better concrete characteristics was also carried out by Grzegorz Prokopski et al [3], Prokopski studied the possibility of a significant increase in the technical properties of granite concrete with the addition of granite dust. The results of his research show that the addition of granite dust can increase the average density of concrete. Prokopski provides his analysis regarding the replacement of some sand with dust, so the microstructure of the cement matrix becomes solid. This is the main reason for increasing the strength of concrete with dust.

In an effort to improve the technical properties of concrete, various studies were carried out using waste materials as concrete mixtures. It is hoped that in addition to improving the technical properties of concrete, it can also increase the added value of the waste material. Several studies that use waste materials as a building block for concrete include Taehwan Kim [4] who uses fly ash as a building block for concrete. Kim conducted a study on the use of 20 different types of fly ash, which were grouped into 4 groups based on similar chemical compositions, then the concrete mixture made from fly ash from the four groups measured the compressive strength and electrical resistivity of the surface, related to the performance of the concrete. The results showed that 
the use of fly ash was promising as a concrete mixture. Anamarie Cotto-Ramos [5] uses recycled plastic and cementitious additives to replace natural aggregates and Portland cement. This research was conducted to observe the effect of adding fly ash (FA), nano-silica (nS), and recycled plastics on the cost and environmentally friendly mechanical properties of structural concrete. The results showed that $44 \%$ of coarse aggregate could be replaced with plastic when adding $2.5 \% \mathrm{nS}$ and $10 \%$ FA (weight $\mathrm{CM}$ ). The ion penetration test results further show that concrete with plastic, FA, and $\mathrm{nS}$ is more durable than conventional concrete. Gérard-PhilippeZéhil [6] studied the effect of cross-linked polyethylene (XLPE) waste on concrete performance, by examining the fresh and hard properties of several sets of mixtures made with various cement and free water contents. XLPE is shredded into various sizes and mixed up to $8 \%$ of the mass of cement. The results of Zehil's research indicated that the workability of concrete and air content was slightly affected by XLPE inclusion, while the unit weight decreased due to the difference in density between the aggregate and the XLPE flake. Another waste material that has the potential to form concrete is sawdust, which is waste from sawmills in the furniture industry. This sawdust is very abundant and has the potential as an additional ingredient in the concrete component as ballast for offshore oil and gas pipelines. The use of sawdust from sawmills in the wood industry as a mixture for concrete pipes has the potential to increase the added value of sawdust.

This study aims to obtain data on the use of sawdust with grain size of 700 mesh as a constituent material for oil and gas concrete pipelines in various compositions for water absorption and compressive strength.

\section{METHOD}

This research was conducted experimentally by using sawdust as an additional material in the formation of concrete. Experiments were carried out on various compositions of sawdust: $5 \%$ by weight of the mixture (4 specimens), $10 \%$ by weight of the mixture (4 specimens), $15 \%$ by weight of the mixture ( 5 specimens) and $20 \%$ by weight of the mixture ( 5 specimens).

Experiments of sawdust with a composition of $5 \%$ by weight of the mixture were carried out with the provisions of the ratio of sawdust to $5 \%$ iron ore, the ratio of iron ore to cement 1: 4, the ratio of water and cement to $0.5 \%$. Sawdust experiments with a composition of $10 \%$ by weight of the mixture were carried out with the provisions of the ratio of sawdust to $10 \%$ iron ore, the ratio of iron ore to cement $1: 4$, the ratio of water and cement to $0.5 \%$. Experiments of sawdust with a composition of $15 \%$ by weight of the mixture were carried out with the provisions of the ratio of sawdust to iron ore of $15 \%$, the ratio of iron ore to cement $1: 4$, the ratio of water and cement to $0.5 \%$. Experiments of sawdust with a composition of $20 \%$ by weight of the mixture were carried out with the provisions of the ratio of sawdust to $20 \%$ iron ore, the ratio of iron ore to cement 1: 4 , the ratio of water and cement to $0.5 \%$. In this experiment, the materials used as a constituent of concrete consisted of type 2 cement with a specific gravity of $3000 \mathrm{~kg} / \mathrm{m}^{3}$, iron ore with a specific gravity of $4500 \mathrm{~kg} / \mathrm{m}^{3}$, water with a specific gravity of $1000 \mathrm{~kg} / \mathrm{m}^{3}$ and sawdust from teak wood. from sawmills' waste in the Blora regency, Central Java Province. Each specimen is then tested to obtain the data for specific gravity, water absorption and compressive strength. Compressive strength testing on specimens was carried out with a curing time of 7 (seven) days and 14 (fourteen) days. Figure 1 shown composition on various concrete pipe.

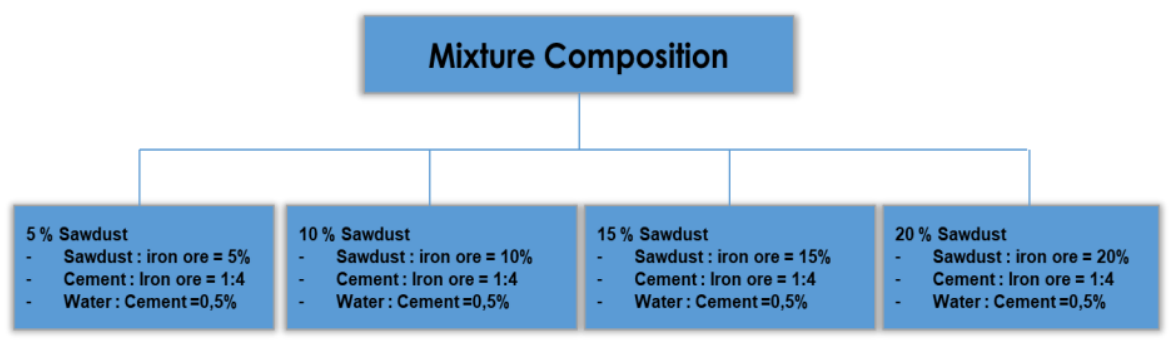

Figure 1 mixture composition on various concrete pipe

Density testing and water absorption of specimens use standard testing methods with reference to ASTM C642: Standard Test Method for Density, Absorption, and Voids in Hardened Concrete. Compressive strength testing uses standard testing methods with reference to ASTM C39: Standard Test Method for Compressive Strength of Cylindrical Concrete Specimens

\section{RESULT AND DISCUSSION}

\subsection{Result}

The test results on specimens with various variations in the composition of the weight of sawdust to the weight of the concrete pipe mixture obtained data on density, water absorption and compressive strength as shown in Table 1 below. 
Table 1. Density, water absorption, and compressive test results

\begin{tabular}{|c|c|c|c|c|c|c|c|c|c|}
\hline \multirow{2}{*}{$\begin{array}{l}\text { Mixture Composition } \\
\text { - Cement : Iron Ore = } 1: 4 \\
\text { - Water : Cement }=0,5 \%\end{array}$} & \multirow{2}{*}{$\begin{array}{l}\text { Specimen } \\
\text { Code }\end{array}$} & \multicolumn{2}{|c|}{$\begin{array}{l}\text { Specimen } \\
\text { Density }\end{array}$} & \multicolumn{2}{|c|}{$\begin{array}{l}\text { Water } \\
\text { Absorption } \\
\end{array}$} & \multicolumn{2}{|c|}{$\begin{array}{l}\text { Compressive } \\
7 \text { day }\end{array}$} & \multicolumn{2}{|c|}{$\begin{array}{l}\text { Compressive } \\
14 \text { day }\end{array}$} \\
\hline & & \multicolumn{2}{|c|}{$(\mathrm{kg} / \mathrm{m3})$} & \multicolumn{2}{|c|}{$(\%)$} & \multicolumn{2}{|c|}{ (Mpa) } & \multicolumn{2}{|c|}{ (Mpa) } \\
\hline \multirow{4}{*}{$\begin{array}{l}5 \% \quad \text { Sawdust } \\
\text { (Sawdust : Iron Ore }=5 \%)\end{array}$} & SK5-1 & 2620 & \multirow{4}{*}{$\begin{array}{l}\text { Avg : } \\
2642\end{array}$} & 1.14 & \multirow{4}{*}{$\begin{array}{l}\text { Avg : } \\
1.132\end{array}$} & 13.55 & \multirow{4}{*}{$\begin{array}{l}\text { Avg : } \\
12.06\end{array}$} & - & \multirow{4}{*}{$\begin{array}{l}\text { Avg : } \\
14.71\end{array}$} \\
\hline & SK5-2 & 2650 & & 1.13 & & 10.75 & & - & \\
\hline & SK5-3 & 2640 & & 1.13 & & - & & 15.40 & \\
\hline & SK5-4 & 2660 & & 1.13 & & - & & 14.02 & \\
\hline \multirow{4}{*}{$\begin{array}{lr}10 \% & \text { Sawdust } \\
\text { (Sawdust }: \text { Iron Ore }=10 \%)\end{array}$} & SK10-1 & 2400 & \multirow{4}{*}{$\begin{array}{l}\text { Avg : } \\
2430\end{array}$} & 2.08 & \multirow{4}{*}{$\begin{array}{l}\text { Avg : } \\
2.374\end{array}$} & 7.76 & \multirow{4}{*}{$\begin{array}{l}\text { Avg : } \\
7.78\end{array}$} & - & \multirow{4}{*}{$\begin{array}{l}\text { Avg : } \\
10.75\end{array}$} \\
\hline & SK10-2 & 2430 & & 2.88 & & 7.80 & & - & \\
\hline & SK10-3 & 2440 & & 2.87 & & - & & 11.55 & \\
\hline & SK10-4 & 2450 & & 2.45 & & - & & 9.95 & \\
\hline \multirow{5}{*}{$\begin{array}{lr}15 \% & \text { Sawdust } \\
\text { (Sawdust }: \text { Iron Ore }=15 \%)\end{array}$} & SK15-1 & 2210 & \multirow{5}{*}{$\begin{array}{l}\text { Avg : } \\
2230\end{array}$} & 5.88 & \multirow{5}{*}{$\begin{array}{l}\text { Avg : } \\
4.49\end{array}$} & 5.46 & \multirow{5}{*}{$\begin{array}{l}\text { Avg : } \\
5.83\end{array}$} & - & \multirow{5}{*}{$\begin{array}{l}\text { Avg : } \\
7.59\end{array}$} \\
\hline & SK15-2 & 2230 & & 5.38 & & 6.20 & & - & \\
\hline & SK15-3 & 2210 & & 4.98 & & - & & 7.37 & \\
\hline & SK15-4 & 2240 & & 4.46 & & - & & 7.82 & \\
\hline & SK15-5 & 2250 & & 4.00 & & - & & - & \\
\hline \multirow{5}{*}{$\begin{array}{lr}20 \% & \text { Sawdust } \\
\text { (Sawdust }: \text { Iron Ore }=20 \%)\end{array}$} & SK20-1 & 2080 & \multirow{5}{*}{$\begin{array}{l}\text { Avg : } \\
2040\end{array}$} & 4.81 & \multirow{5}{*}{$\begin{array}{l}\text { Avg : } \\
5.87\end{array}$} & - & \multirow{5}{*}{$\begin{array}{l}\text { Avg } \\
: 3.18\end{array}$} & - & \multirow{5}{*}{$\begin{array}{l}\text { Avg : } \\
4.62\end{array}$} \\
\hline & SK20-2 & 2050 & & 5.85 & & - & & 5.2 & \\
\hline & SK20-3 & 2050 & & 5.85 & & 3.14 & & - & \\
\hline & SK20-4 & 2040 & & 6.37 & & 3.21 & & - & \\
\hline & SK20-5 & 2000 & & 6.50 & & - & & 4.05 & \\
\hline
\end{tabular}

\subsection{Discussion}

The data from the specimen test results on the density value shown as Figure 2 that the addition of the weight composition of sawdust to the weight of the concrete mixture shows a tendency to decrease the density value of the concrete. The decrease in concrete density is due to the increasing weight composition of sawdust which has a lighter specific gravity than iron ore and cement. Density data from the results of this study can be used as a reference in the application of using sawdust as a constituent material in concrete as ballast for oil and natural gas pipes. Figure 3 shows graph of the percentage of sawdust VS water absorption.

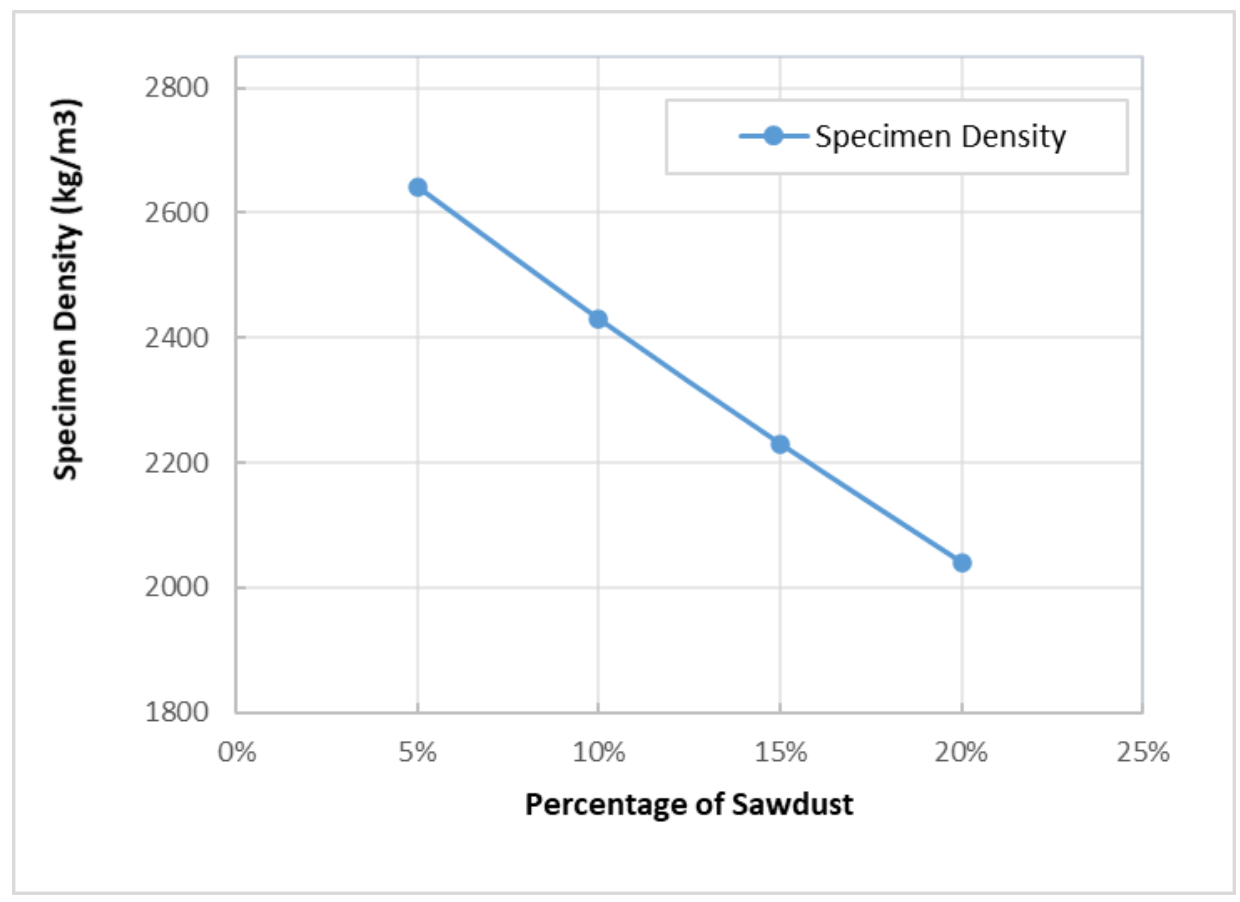

Figure 2 Graph of the percentage of sawdust VS specimen density 


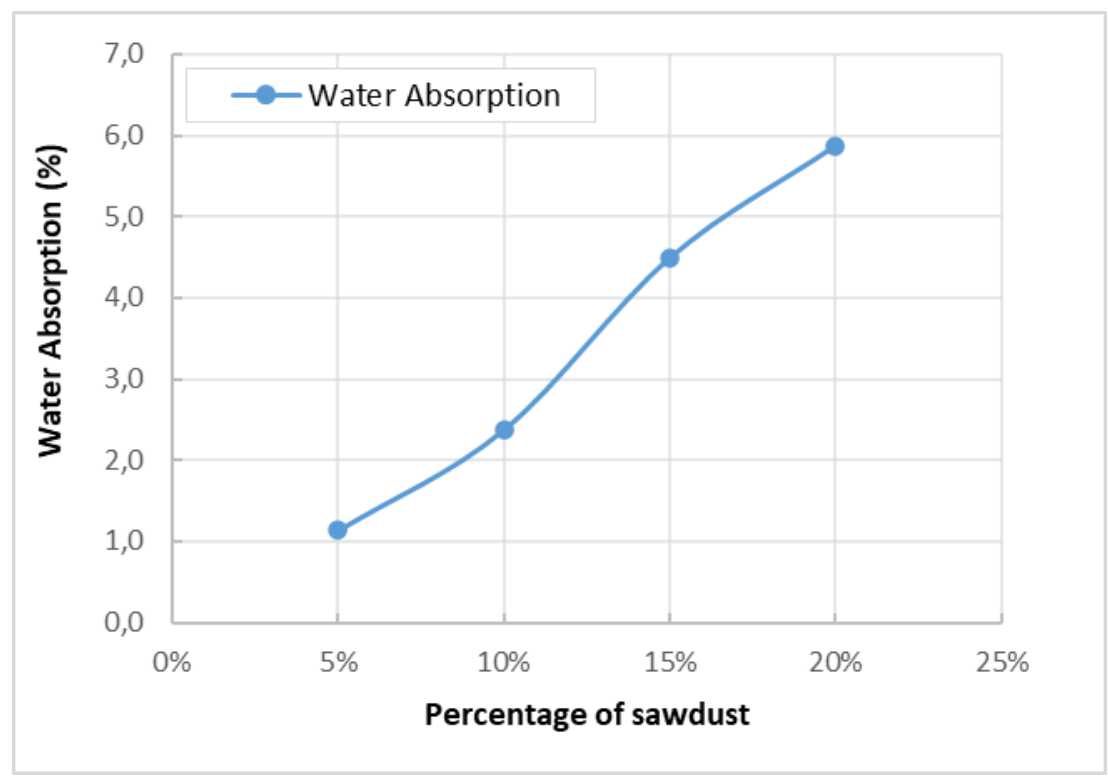

Figure 3 Graph of the percentage of sawdust VS water absorption

The results of specimen testing on water absorption showed that the addition of sawdust weight composition to the weight of the concrete mixture showed a tendency to increase the value of water absorption of concrete. The increase in the value of water absorption was due to the increasing addition of the sawdust weight composition resulting in the increasing volume of the permeable pore space in the concrete. The permeable pore space volume becomes larger than standard concrete and the data from this test result can be taken into consideration that the use of this type of concrete is recommended to only be used as a ballast for oil and natural gas pipes used in shallow water operation areas. Figure 4 shown graph of the percentage of sawdust VS compressive test.

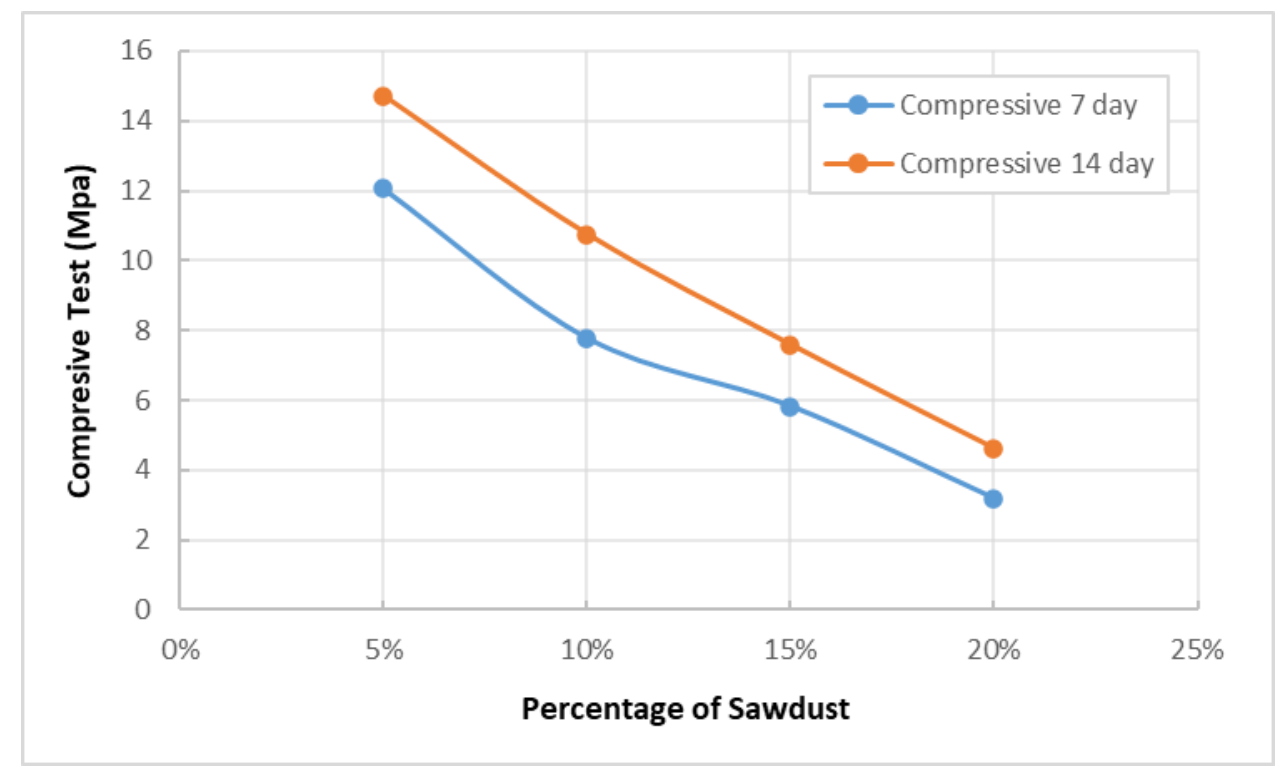

Figure 4 Graph of the percentage of sawdust VS compressive test

The test results of specimens on the compressive strength value with a curing time of 7 (seven) days and 14 (fourteen) days show that the addition of the weight composition of sawdust to the weight of the mixture results in a decrease in the compressive strength value of the concrete. The compressive strength value with a curing time of 14 days produces a better number than the curing time of 7 days, this shows that the formation of the inter-phase strength of the concrete-forming mixture is better by increasing the curing time of the specimen. The hydration of the mixture with a longer curing time is also a factor that affects the quality of compressive strength. In general, for each curing time treatment shows the same tendency to decrease the compressive strength of concrete, this can be caused by various factors, for example the increase in concrete porosity due to the 
increase in the composition of sawdust. Determination of the composition of water as a binder whose value is constant can affect the quality of the concrete bonding due to the addition of the weight composition of sawdust. The decrease in the compressive strength value shows that there is a decrease in stress in the transition zone after the addition of sawdust to the concrete mixture. Based on this experimental data, the use of concrete with the addition of sawdust as a mixture can be used by considering the compressive strength data at various compositions of the sawdust mixture.

\section{CONCLUSION}

The addition of sawdust composition reduced density and compressive strength and increased water absorption. The increase in curing time will increase the compressive strength of the concrete mixture. Sawdust can be used as a concrete mixture that functions as a ballast for offshore oil and gas pipes according to the desired load requirements.

\section{ACKNOWLEDGMENTS}

This research funding comes from PEM Akamigas Cepu research fund, in collaboration with PT. Indal Steel Pipe as the party that has collaborated in this research. Thank you to PEM Akamigas Cepu's management, management and technicians of PT. Indal Steel Pipe, and all those who helped in this research.

\section{REFERENCES}

[1] Kamran Amini, Payam Vosoughi, Halil Ceylan and Peter Taylor, "Effect of mixture proportions on concrete performance," Construction and Building Materials, vol. 212, pp. 77-84, 2019.

[2] Aref Shafiei Dastgerdi, Robert J.Peterman, KyleRiding, and B. TerryBeck, "Effect of concrete mixture components, proportioning, and compressive strength on fracture parameters," Construction and Building Materials, vol. 206, pp. 179-192, 2019.
[3] Grzegorz Prokopski, Vitaliy Marchuk, and Andriy Huts, "The effect of using granite dust as a component of concrete mixture," Case Studies in Construction Materials, 2019.

[4] Taehwan Kim, M. Tyler Ley, Shinhyu Kang, Jeffrey M. Davis, Seokhyeon Kim, and Pouya Amrollah, "Using particle composition of fly ash to predict concrete strength and electrical resistivity," Cement and Concrete Composites, 2019.

[5] Anamarie Cotto-Ramos, Saylisse Dávila, Wandaliz Torres-García, and Arsenio Cáceres-Fernández, "Experimental design of concrete mixtures using recycled plastic, fly ash, and silica nanoparticles," Construction and Building Materials, vol. 254, pp. 119-207, 2020.

[6] Gérard-PhilippeZéhilaJoseph J.Assaad, "Feasibility of concrete mixtures containing cross-linked polyethylene waste materials," Construction and Building Materials, vol. 226, Pages 1-10, 2019.

[7] Zhi Xing, Chafika Djelal, Yannik Vanhove, Hassina Kada, "Wood waste in concrete blocks made by vibrocompression," Environ. Process, Suppl 1, S223-232, 2015.

[8] J.G. Ndong Engone, Y. Vanhove, C. Djelal, H. Kada,"Optimizing mortar extrusion using poplar wood sawdust for masonry building block," International Journal Advamced Manufacturing Technology, Vol. 95, pp 3769-3780, 2018.

[9] ASTM International, "Standard Test Method for Density, Absorption, and Voids in Hardened Concrete (ASTM C 642)," ASTM International, 2013.

[10] ASTM International, "Standard Test Method for Compressive Strength of Cylindrical Concrete Specimens (ASTM C 39/ C 39M)," ASTM International, 2020. 